\title{
A new species of Wrightoporia (Basidiomycetes) from China
}

\author{
YU-CHENG DAI
}

\begin{abstract}
DAI, Y.C. 1994: A new species of Wrightoporia (Basidiomycetes) from China. Karstenia 35:84-85. Helsinki. ISSN 0453-3402

A new polypore, Wrightoporia rubella Y.C.Dai, is described from Beijing, China. It is easily distinguished from the other species of the genus by its strongly developed, vinaceous rhizomorphs, pale brown context, generative hyphae without clamp connections and somewhat larger spores than in the other species. The differences between it and related species are discussed.
\end{abstract}

Key words: China, polypores, taxonomy, Wrightoporia

Yu-Cheng Dai, Department of Botany, P.O. Box 47, FIN-00014 University of Helsinki, Finland

\section{Introduction}

The genus Wrightoporia (Polyporaceae, Aphyllophorales) was described by Pouzar (1966) for Poria lenta Overh. \& J.Lowe and P. avellanea Bres. because of a unique combination of characters: amyloid and ornamented spores, linked with dextrinoid and cyanophilous skeletal hyphae. Later, other species were transferred to the genus or described as new in it, particularly species from tropical areas (Ryvarden 1982, 1983, 1989; Ryvarden \& Johansen 1980; Rajchenberg 1983, Rajchenberg \& David 1990; David \& Rajchenberg 1985, 1987; Zheng \& Bi 1987). These additions gave the genus a wider concept than expressed in the original definition; it is now understood to include annual to perennial species, having resupinate to pileate basidiocarps, dimitic hyphal system, dextrinoid or non-dextrinoid and cyanophilous to acyanophilous skeletal hyphae, and smooth to asperulate spores having a weakly to strongly amyloid wall (Ryvarden 1982). Subsequently some species without clamps were included in the genus (David \& Rajchenberg 1985; Ryvarden 1989, Zheng \& Bi 1987). Finally,
David and Rajchenberg (1987) reevaluated the genus and noted the similarities with Amylonotus Ryvarden, which was originally described by its dominating golden brown skeletal hyphae (Ryvarden 1975). They expanded the concept of Wrightoporia by including Amylonotus in it, and so the presence of gloeoplerous hyphae and gloeocystidia or pseudocystidia was added to the generic characters. Furthermore, Rajchenberg and David (1990) included one distinctly monomitic species in the genus, and Teixeira (1992) transferred Amylosporus campbellii (Berk.) Ryvarden to Wrightoporia, without, however, offering any explanation.

During a study of wood-rotting fungi in northern China (Dai \& Niemelä 1994), two specimens of a resupinate polypore with strong rhizomorphs were collected from Beijing. Both evidently belonged to the genus Wrightoporia, since they possessed a dimitic hyphal system, dextrinoid skeletal hyphae, gloeoplerous hyphae and gloeocystidia, and finely echinulate, amyloid spores. They did not fit any known species in the genus, however, The two specimens are in very good condition, and I describe them here as a new species. 


\section{Methods}

I used Cotton Blue (CB) when measuring and drawing the figure. Spores were measured from sections cut from the tubes. IKI stands for Melzer's reagent and $\mathrm{KOH}$ for $5 \%$ potassium hydroxide; $\mathrm{CB}+$ means cyanophilous and $\mathrm{CB}-$ acyanophilous. In determining the variation of the spore size, $5 \%$ of the measurements were excluded from each end of the range and are given in parentheses. The following abbreviations are used in the text: $\mathrm{L}=$ mean spore length (arithmetical mean of all spores), $\mathrm{W}=$ mean spore width (arithmetical mean of all spores), $Q=$ quotient of the mean spore length and the mean spore width (L/W ratio), $(n=x / y)=x m e a s u r e m e n t s$ of spores (basidia, hyphae, gloeocystidia) from y specimens. The width of a basidium was measured at the thickest part and the length was measured from the apex (sterigmata excluded) to the subbasidial septum. Sections were studied at magnification up to $\times 1250$ by using a Leitz Diaplan microscope and phase contrast illumination. Drawings were made with the aid of a drawing tube. For a more detailed description of the methods, see Niemelä (1985). Colour terms are according to Rayner (1970).

\section{Wrightoporia rubella Y.C.Dai, sp. nova -} Fig. 1.

Fructificatio annua, resupinata vel effusoreflexa, pori pallide infuscata vel erubescentes, 3-4 per $\mathrm{mm}$; systema hypharum dimiticum; hyphae generatoriae afibulatae, hyphae skeletales crassitunicatae, dextrinoideae; sporae copiosae, late ellipsoideae vel subglobosae, amyloideae, 4-6 × 3-4.2 $\mu \mathrm{m}$.

Type: China. Beijing: Xiangshan, on very rotten wood of angiosperm, 26.IX.1993 Dai 1339 (H, holotype).

\section{Additional specimen examined}

Beijing. Yiheyuan, on rotten wood of angiosperm, 29.IX.1993 Dai 1407b (HMAS).

Basidiocarps annual, resupinate to effusedreflexed, cottony soft and easily separated from the substrate when fresh, becoming slightly tougher upon drying, margin sterile, pale ochraceous with strong rhizomorphs which form a cottony pseudopileus, the rhizomorphs are livid vinaceous to brown vinaceous; pore surface cream to pinkish when fresh, becoming ochraceous when dry. Pores round or angular, $(2-) 3-4(-5)$ per $\mathrm{mm}(\mathrm{n}=62 / 2)$. Subiculum $1-2 \mathrm{~mm}$, tough, pinkish brown, becoming reddish black with $\mathrm{KOH}$; tube layer similar to pore surface, tubes tough, about $1 \mathrm{~mm}$ long.

Hyphal system dimitic with skeleto-binding hyphae; generative hyphae without clamp connections, skeletal hyphae thick-walled, some of them branched like "binding" hyphae. Hyphae unchanged in $\mathrm{KOH}$, but exuding an oily substance into the mounting medium.

Rhizomorphs. Generative hyphae and gloeoplerous hyphae similar to those in trama. Skeletal hyphae dominating in the structure, thick-walled, occasionally branched, interwoven, dextrinoid, $\mathrm{CB}$ - or weakly $\mathrm{CB}+$, narrower than those in subiculum and trama, $(1.5-) 2-4(-5) \mu \mathrm{m}$ $(n=40 / 2)$.

Subiculum. Generative hyphae hyaline, branched, thin-walled, without clamps, (2-)2.5-5(-6) $\mu \mathrm{m}$ in diam $(n=66 / 2)$. Skeletal hyphae thick-walled, straight to flexuous, some of them branched, dextrinoid, $\mathrm{CB}-$ or weakly $\mathrm{CB}+,(2.5-) 3-5.5(-6.5) \mu \mathrm{m}$ in diam $(n=65 / 2)$. Structure next to wood with subparallel, wide $(5-10 \mu \mathrm{m}$ in diam, $\mathrm{n}=34 / 2)$, thin- to fairly thick-walled generative hyphae, which are simple-septate frequently, hyaline, nondextrinoid, $\mathrm{CB}$ - or weakly $\mathrm{CB}+$. In addition, there are equally wide, branched gloeoplerous hyphae, with the same reactions in IKI and CB as the generative hyphae, but containing an oily substance that is blue in CB.

Tubes. Tramal generative hyphae hyaline, interwoven with skeletal hyphae, $(2-) 3-5(-5.5) \mu \mathrm{m}$ in diam $(n=62 / 2)$. Skeletal hyphae thick-walled, straight to flexuous, rarely branched, dextrinoid, $\mathrm{CB}-$ or weakly $\mathrm{CB}+,(2-) 3-5(-5.5) \mu \mathrm{m}$ in diam $(n=63 / 2)$. Gloeoplerous hyphae similar to those in subiculum. Gloeocystidia present in hymenium but not common, variable in shape and dimension, 25-45 × 5-14 $\mu \mathrm{m}(\mathrm{n}=12 / 2)$, some of them hyaline, some blue in $\mathrm{CB}$. Basidia clavate, with a simple basal septum and four sterigmata, $(14-) 20-38(-42) \times 5-7.2(-8) \mu \mathrm{m}(\mathrm{n}=$ $48 / 2$ ); basidioles slightly smaller, but similar in shape.

Spores. Basidiospores broadly ellipsoid to subglobose, with finely echinulate ornamentation (very easily seen in Melzer's reagent, but appearing almost smooth in $\mathrm{CB}$ ), thin-walled to fairly thickwalled, distinctly amyloid, $\mathrm{CB}-.4-6(-7) \times(2.3-) 3-$ 4.2(-4.8) $\mu \mathrm{m}, \mathrm{L}=5.13, \mathrm{~W}=3.39, \mathrm{Q}=1.17-1.44$ ( $\mathrm{n}=71 / 2)$.

Etymology: rubellus (Lat., adj.), red, referring to the colour of the rhizomorphs.

Ecology and type of rot. Very little can be said about the ecology of the new species. The two specimens were found in parks strongly influenced by man. One specimen was growing on a 

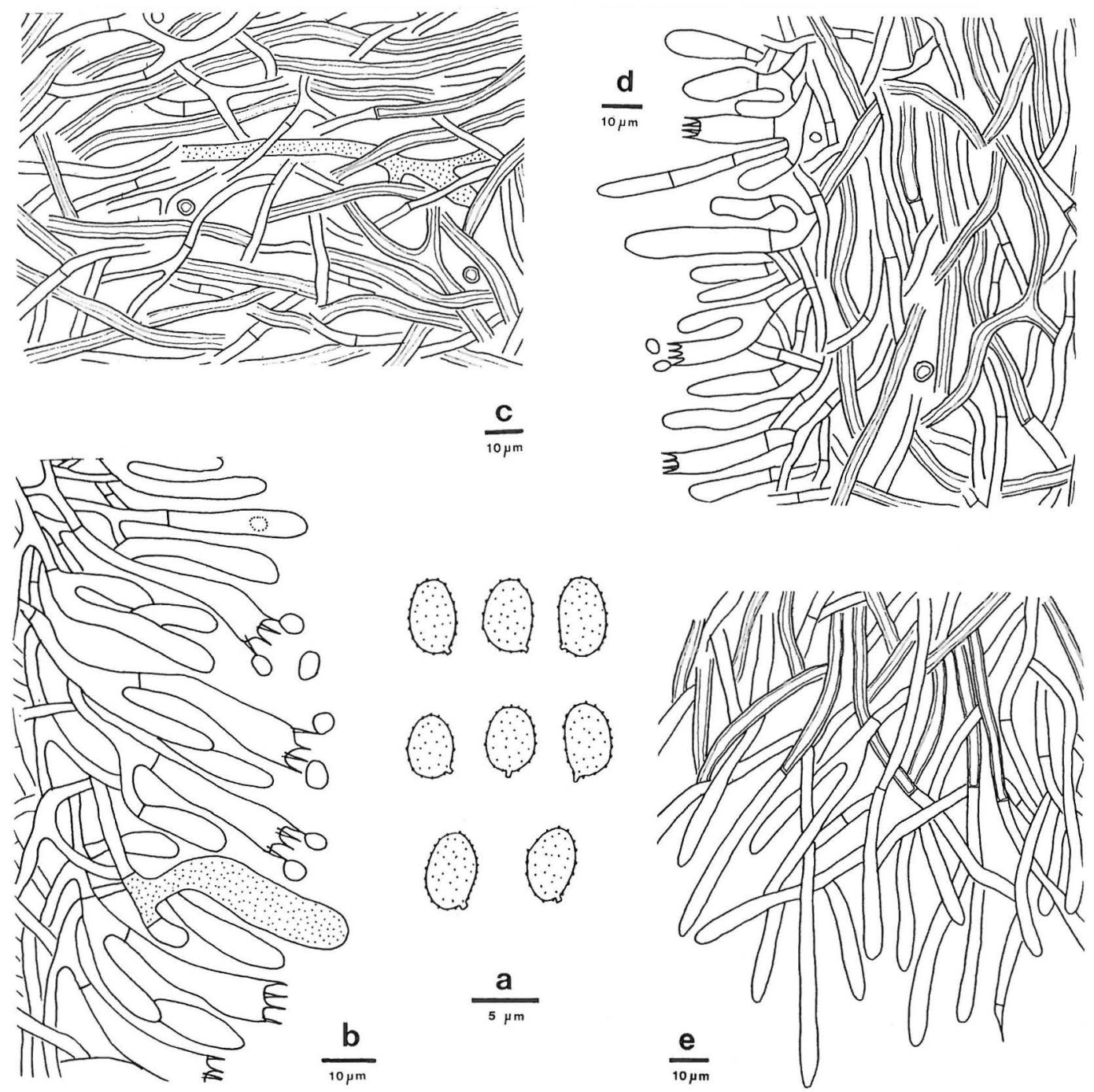

Fig. 1a-e. Microscopical structures of Wrightoporia rubella Y.C.Dai, drawn from the type - a) basidiospores, b) basidia, basidioles and a gloeocystidium, c) a vertical section through subiculum, d) a vertical section through trama, e) dissepiment edge in a vertical section.

decorticated fallen trunk which was mostly decayed by a species of the Corticiaceae. The type of rot could not be determined.

\section{Discussion}

The thick-walled hyphae are mostly unbranched and can be described as typical skeletal hyphae. However, some of them bear a few branches, agreeing with Corner's definition of skeletobinding hyphae (1981).

The strongly rhizomorphic fruit body, pale brown context, dimitic hyphal system, dextrinoid skeletal hyphae, and fairly large, ornamented amyloid spores are the main characters of Wrightoporia rubella. The new taxon lacks clamp connections and has acyanophilous skeletal to skeleto-binding hyphae, but otherwise shares all the basic characters with the type 
species. Several other species in the genus likewise exhibit agreement with the essential characters of the genus while deviating in one character or another. For example, W. cylindrospora Ryvarden has smooth spores and non-dextrinoid skeletal hyphae, W. cinnamomea Ryvarden has non-dextrinoid skeletal hyphae, and W. perplexa Ryvarden has simple septa and non-dextrinoid skeletal hyphae in the subiculum. The new species agrees well with the concept of Wrightoporia.

Among the species of Wrightoporia, only three, besides $W$. rubella, lack clamp connections in generative hyphae: W. perplexa, W. subadusta G.Y.Zheng \& Z.S.Bi, and W. tropicalis (Cooke) Ryvarden. The last-mentioned was described as a clamp-bearing species by Ryvarden (1982) and Ryvarden \& Johansen (1980), but it is very difficult to observe the septa. Later, after restudying specimens from Africa and America and carrying out cultural characters, David and Rajchenberg $(1985,1987)$ described $W$. tropicalis as a simple-septate species.

$W$. perplexa is distinctly pileate, nonrhizomorphic, and lacks gloeoplerous hyphae and gloeocystidia, whereas $W$. rubella is rhizomorphic and has gloeoplerous hyphae and gloeocystidia. The basal part of the context is slightly amyloid in $W$. perplexa, unlike in $W$. rubella. The critical differentiating characters are the chemical reactions of the spores: in $W$. perplexa they are inamyloid and in W. rubella amyloid.

W. subadusta is typically pileate, nonrhizomorphic, has smaller pores (6-8 per mm vs. 3-4 per $\mathrm{mm}$ in $W$. rubella), and lacks gloeoplerous hyphae and gloeocystidia. It has setal hyphae in the context and clamped basidia, and smooth spores. These characters are not present in $W$. rubella. $W$. tropicalis is a resupinate species, but it is perennial, without rhizomorphs, and has smaller pores (6- 8 per $\mathrm{mm}$ ) and spores $(3-4 \times 2-3 \mu \mathrm{m})$.

W. africana I.Johans. \& Ryvarden and $W$. avellanea (Bres.) Pouz. are the other resupinate, rhizomorphic species of the genus, but differ from $W$. rubella in having clamp connections in the generative hyphae, unbranched and narrow skeletal hyphae (less than $2.5 \mu \mathrm{m}$ in diam vs. 3$6 \mu \mathrm{m}$ in W. rubella), and smaller spores (3-3.5 $\times$ $2.5-3 \mu \mathrm{m}$ and 3.5-4.5 $\times 2.5-3.5 \mu \mathrm{m}$, respectively). Both species have A cream-coloured pore surface, and rhizomorphs and context that are different from W. rubella.

The gloeoplerous hyphae and gloeocystidia of the new taxon are supporting a prediction by David and Rajchenberg (1987) that these two characters would turn out to be important features in the genus. The species keys out under point 2 in the key of David and Rajchenberg (1987:203).

\section{Comparison material examined}

Wrightoporia africana

Kenya. Eastern Prov.: Nyeri Dist., Mt. Kenya S slope, Regati Forest Sta., 2 200-2 300 m, 2-3.II.1973 Ryvarden 9775 (O). Malawi. Southern Prov.: Mulanje Dist., Mulanje Mts., Lichenya Plateau, 1 800-2 000 m, 9-10.V.1973 Ryvarden 11414 (O). Tanzania. Morogoro Prov.: Morogoro Dist., Uluguru Mts., Morning Side Res. Sta., c. $5 \mathrm{~km} \mathrm{~S}$ of Morogoro, $1500-2100 \mathrm{~m}, 24-26 . I I .1973$ Ryvarden $1112(\mathrm{O})$.

\section{Wrightoporia avellanea}

Tanzania. Morogoro Prov.: Morogoro Dist., Uluguru Mts., Morning Side Res. Sta., c. $5 \mathrm{~km} \mathrm{~S}$ of Morogoro, 1500 2100 m, 24-26.II.1973 Ryvarden 11046 (O). U.S.A. Florida: Silver Springs, on cabbage palm, 8.VIII.1959 Lowe 4331 (H, sub n. Poria heteromorpha Murrill).

Wrightoporia lenta

U.S.A. North Carolina: Highland, on pine stump, 3.IX.1950 Lowe 3859 (O).

Acknowledgements. Financial support from the Academy of Finland (Project No. 1012426, 1993-1994) is gratefully acknowledged. I would like to express my gratitude to Prof. Tuomo Niemelä (Helsinki) for his guidance, generous help in solving problems, and for the revision of the manuscript. Pertti Renvall (Helsinki) allowed me to study some specimens on loan from Prof. Leif Ryvarden (Oslo), and Prof. Teuvo Ahti (Helsinki) prepared the Latin description; warm thanks are due both.

\section{References}

Corner, E.J.H. 1981: The agaric genera Lentinus, Panus, and Pleurotus. - Nova Hedwigia Beih. 69:1-169.

Dai, Y.C. \& Niemelä, T. 1994: Changbai wood-rotting fungi 1. A new species of Anomoporia (Basidiomycetes) from China. - Ann. Bot. Fennici 31:65-69.

David, A. \& Rajchenberg, M. 1985: Pore fungi from the French Antilles and Guiana. - Mycotaxon 22:285325.

David, A. \& Rajchenberg, M. 1987: A reevaluation of Wrightoporia and Amylonotus (Aphyllophorales, Polyporaceae). - Canadian J. Bot. 85:202-208.

Niemelä, T. 1985: On Fennoscandian polypores 9. Gelatoporia n. gen. and Tyromyces canadensis, plus 
notes on Skeletocutis and Antrodia. - Karstenia 25:21-40.

Pouzar, Z. 1966: Studies in the taxonomy of the polypores 1. - Ceská Mykol. 20:171-177.

Rajchenberg, M. 1983: New South American resupinate polypores. - Mycotaxon 16:500-506.

Rajchenberg, M. \& David, A. 1990: A new species of Wrightoporia Pouz. (Polyporaceae, Basidiomycetes). — New Zealand J. Bot. 28:186-186.

Rayner, R.W. 1970: A mycological colour chart. - 34 pp., 9 pl. Commonwealth Mycol. Inst., Kew.

Ryvarden, L. 1973: New genera in the Polyporaceae. Norwegian J. Bot. 20:1-5.

Ryvarden, L. 1975: Studies in the Aphyllophorales of Africa 2. Some new species from East Africa. Norwegian J. Bot. 22:25-34.

Ryvarden, L. 1982: Synopsis of the genus Wrightoporia. — Nordic J. Bot. 2:145-149.
Ryvarden, L. 1983: Type studies in the Polyporaceae 14. Species described by N. Patouillard, either alone or with other mycologists. - Occas. Pap. Farlow Herb. 18:1-39.

Ryvarden, L. 1987: New and noteworthy polypores from tropical America. - Mycotaxon 28:540.

Ryvarden, L. 1989: Wrightoporia perplexa nov. sp. (Polyporaceae). - Opera Bot. 100:225-227.

Ryvarden, L. \& Johansen, I. 1980: Preliminary polypore flora of East Africa. - 636 pp. Fungiflora, Oslo.

Teixeira, A.R. 1992: New combinations and new names in the Polyporaceae. - Rev. Brasileira Bot. 15:125-127.

Zheng, G.Y. \& Bi, Z.S. 1987: Three new species of Polyporaceae from the North Guangdong of China. Bull. Bot. Res. 7:73-79.

Received on 15 January 1995 